\title{
Realistic Mathematics Education: A Learning Innovation in Enhancing Students' Algebraic Thinking Ability
}

\author{
Didi Suhaedi \\ \{dsuhaedi@unisba.ac.id ${ }^{1}$ \} \\ Department of Mathematics, Bandung Islamic University
}

\begin{abstract}
Algebra thinking is one of the abilities students must have in learning school algebra. The weak algebraic thinking ability of junior high school students is one part of the problems in mathematics education. One effort to solve these problems is to innovate learning with a realistic mathematics education (RME) approach. This study is a quasiexperiment about improving students' algebraic thinking abilities, with the experimental class using the RME approach and the control class using expository learning. The research sample consisted of 134 eighth grade students of junior high schools in Bandung. The results of the study show that increasing the algebraic thinking ability of students who get learning with an RME approach is better than students who get expository learning at every level of students' initial mathematical knowledge.
\end{abstract}

Keywords: School Algebra, Algebraic Thinking, RME

\section{Introduction}

Algebra is one of the mathematics materials in school which is considered fundamental and important for students to master. It is because algebra is used in daily activity - either implicitly or explicitly. Algebra is used in syntax to create a web address, e-mail, search engines on the internet; to create automation remote control of $\mathrm{TV}$, radio, $\mathrm{LCD}$; to create tsunami wave modeling, population growth modeling, and others; all of these require algebraic logic. Algebra has an important role in technological development [1], as a gatekeeper to future education, and can create job opportunities $[2,3]$.

Unfortunately, algebra is a difficult material for students, specifically for middle school students $[4,5,6,7,8,9,10,11]$. Kriegler and Lee [12] said that the mastery of algebra in equivalence topics by students of eighth-graders in California was twenty-two percent. Kenney and Silver said that students of grade twelve had difficulties in simplifying and solving algebraic equations and inequalities and had great difficulty in translating verbal language into symbolic representation [11].

NRC held a symposium on 27 to 28 May 1997 with the title The Nature and Role of Algebra in the K-14 Curriculum. The first page of the NRC report published in 1998 said that students in the U.S. had some difficulties in learning algebra. The difficulties were stated that the first year of algebra course in the U.S. was so-called as "an unmitigated disaster for most students". Therefore, there should be a solution for algebraic difficulties. Then, what should we do to solve the student's difficulties in learning school algebra? 
One of the attempts to overcome such problems in learning algebra is to make improvements in algebraic learning. RME is an innovative concept in mathematics learning, especially algebra learning. Therefore, this research has been conducted to study algebraic learning and teaching within schools using RME where students' algebraic thinking ability is constructed by exposing students to the concrete situation as a basis for students to get semiconcrete representation, to make semi-abstract representations, and eventually to perform symbolic representation.

\section{Algebraic Thinking}

Algebra is an analysis of changes from a concrete situation to an abstract concept, using variables, making representations and interpretations of a collection of data [13]. Also, algebra is a generalization of arithmetic, learning about number patterns, the study of various procedures and structures, the use and manipulation of symbols to solve real-world problems $[6,14,15]$.

Activities in studying algebra material are: (a) making representations, which consist of generalizations of various expressions and equations based on quantitative situations; (b) carrying out transformations, which consist of using rules for manipulating symbols and changing an expression (or equation) into another form of expression (equation); (c) make generalizations and justifications, which consist of analysis of representations to identify structures, make predictions and prove [16].

What is algebraic thinking? In general, algebraic thinking consists of a series of understandings to translate everyday information (or events) into mathematical language, as an effort to get an explanation and make predictions of a phenomenon [13]. The direction of thinking algebra is to think abstractly, which is the foundation in studying high-level algebra material. Effectiveness in the process of thinking algebra requires several components, namely: (a) making and using mathematical models; (b) record, collect, organize data, search for and expand data patterns; (c) make generalizations as rules and are used in making predictions [13].

Herbert and Brown state that algebraic thinking activities are (a) exploring information from various situations, (b) representing mathematical information with words, diagrams, tables, graphs and equations, (c) interpreting and applying mathematical findings, such as solutions to the unknown, testing hypotheses, and identifying functional relationships [17].

From various views explained above, it could be said, that algebraic thinking is the ability to: (a) create a mathematical model based on the information (or events) that occur in everyday life, (b) make representations mathematical information in words, graphs, or equations; (c) collect, organize, and search patterns of data (as a generalization), which serve as specific rules, (d) make the interpretation, prediction, and application of the results mathematical discovery, (e) develop mathematical reasoning within the framework of algebra by constructing meanings of symbols and algebraic operations, (f) think about the functions, and think about the impact the calculation of a structured system, $(\mathrm{g})$ the process of justifying, solve equations, and problem-solving.

The discussion above provides information that the main problem in thinking algebra starts from concrete situations towards mathematical models that are abstract. This situation corresponds to the level of thinking of eighth-grade students who are in the level of semi-formal thinking (referring to Piaget's cognitive theory) and must master the final part of algebraic thinking, which is abstract. To overcome these problems, a learning innovation is needed that 
can lead students from semi-formal thinking to abstract thinking (formal). One relevant learning innovation is RME.

RME was born in the Netherlands on the ideas of Freudenthal. Freudenthal states that mathematics must be connected to reality, close and relevant to the community of children. The use of realistic contexts is characteristic of RME learning. The term 'realistic' emphasizes that students must try to imagine a given problem situation, and the emphasis is not on the originality of problems. Context does not have to be limited to real-world situations. A fairytale or formal mathematics can be used as the context of a problem if it is 'real' in the minds of students.

Freudenthal considers that mathematics is an activity for students [18], students are active learners, students have the opportunity to construct mathematical concepts (through scaffolding from the teacher) from students' daily situations [19, 20]. This process is called a mathematical concept, which is stated as follows [21].

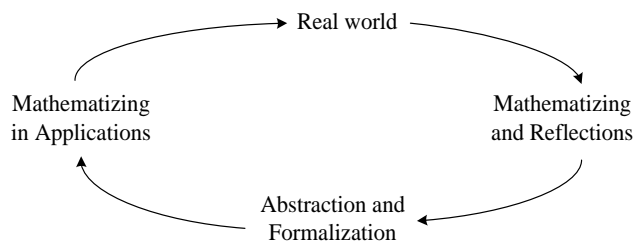

Fig. 1. Conceptual Mathematization.

The description of the concept development process above has no endpoint. This shows that the process is more important than the final result. Whereas the starting point of the process emphasizes conceptions that are well known to students. This is due to the assumption that each student has an initial concept of mathematical ideas.

The three main principles in RME [22] are as follows: guided reinvention and progressive mathematization; didactic phenomenon; self-model development. Guided reinvention means that students have the opportunity to discover their mathematical concepts in solving contextual problems. Contextual problems provide direction for students to form concepts, construct models, apply known concepts, and solve them based on applicable mathematical rules.

Progressive mathematization is done through horizontal and vertical mathematical. The horizontal mathematical process begins with the presence of contextual problems, through the way students look for solutions to these problems. While the processes that occur in mathematical systems, such as the use of certain formulas, are called vertical mathematical [22, $23,24,25,26]$.

In didactic phenomena, mathematics learning, whose orientation to inform students and use ready-made mathematics to solve problems, changes in such a way that the problem becomes the primary media to start learning mathematics. This way enables students to solve their problems in their ways. In this respect, students are expected to move towards horizontal and vertical mathematization. Horizontal mathematization is done through informal steps before students enter more formal mathematics. The process of horizontal-vertical mathematization is expected to give students more opportunities to understand more abstract mathematics easily $[23,27,28,29,30]$.

The existence of a contextual problem presented at the beginning of learning activities enables students to find a variety of ways to solve the problems. Therefore, the students get used to free-thinking and brave to express their arguments. This could happen because the students can use their ways which are quite probably different from their friends' way or even students 
use ways different from their teacher's way; students' ways remain true and lead to the correct result. This reveals a didactic phenomenon, which provides information that the mathematics learning process does not stay at the teacher-centered, but dramatically change into studentcentered learning.

The principle of self-developed model bridges the gap between informal and formal mathematics knowledge developed from students. Mathematical models are emerged and developed independently based on mathematical models that have been known by students. Initiated with contextual cases taken from students' real situations, the model of a given situation (informal form) is found and then this step is followed by the discovery of model for previous form (an informal) in such a way that solution is solved in the form of standard mathematical knowledge.

From the above principles, Gravemeijer and Treffers [22, 31] describes learning with realistic mathematics into five activities as follows. (a) phenomenological exploration. Phenomenon exploration activities direct students to use their informal mathematical knowledge in solving problems that they face; (2) bridging by vertical instruments that emphasize on models and schemata situation, rather than on a too formal way. A given problem-solving activity is expected to bridge the gap between intuitive level and formal level; (3) student contribution based on students' production and construction within their learning activities, (4) interactivity which is manifested in the form of intervention, discussion, cooperation, and evaluation in learning process, (5) intertwining where the studying topic is not presented separately from the other topic, but related to one another.

\section{Research Method}

The research method used in this study is quasi-experimental with pretest-posttest control, using the experimental and control groups. The experimental class receives learning by using RME and a control class receives expository learning. The research sample consists of 134 junior high school students from two Junior High School in Bandung. The impact of treatment of learning can be analyzed in general, then the sample was divided into 69 students from the RME class and 65 students from the expository class. The analysis of the learning impact can be done more specifically according to the students' initial mathematical knowledge, so the data is grouped as follows: (a) the RME class has 17 students of top initial mathematical knowledge, 25 students of middle initial mathematical knowledge, and 27 students of low initial mathematical knowledge; (b) expository class there are 22 students of top initial mathematical knowledge, 22 students of middle initial mathematical knowledge, and 21 students of low initial mathematical knowledge.

\section{Result and Discussion}

\subsection{Data Analysis of Algebraic Thinking Ability Based Learning}

Data of algebraic thinking ability of 69 students from the RME class and 65 students from the expository class which consists of the pretest average, posttest average, average of increase (N-Gain) and standard deviation (SD) based on learning approaches is as follows. 
Table 1. Data on algebraic thinking based learning.

\begin{tabular}{lrrrrrr}
\hline \multirow{2}{*}{ Statistic } & \multicolumn{3}{c}{ RME Learning } & \multicolumn{3}{c}{ Expository Learning } \\
\cline { 2 - 7 } & Pretest & \multicolumn{1}{c}{ Posttest } & N-Gain & Pretest & Posttest & N-Gain \\
\hline Average & 5,92754 & 15,79710 & 0,61641 & 5,98462 & 12,56923 & 0,41132 \\
SD & 2,31567 & 3,22025 & 0,18495 & 1,45229 & 2,83378 & 0,17404 \\
\hline
\end{tabular}

Table 1 shows that before the study, the algebraic thinking ability average of students who got the RME method is of 5,92754. The score is slightly the same with the score of algebraic thinking for students getting expository learning, which is 5,98462. After RME learning, students' algebraic thinking ability increases. Students who got RME to get an average of algebraic thinking ability with a score of 15,79710 (enhancing as much as 0,61641 ); on the other hand, students who got expository learning gets an average of algebraic thinking ability with the score 12,56923 (enhancing as much as 0,41132 ).

The result above indicates that there is a difference in students' algebraic thinking between RME and expository learning. Significant differences from the results of the two learning are presented in the following table.

Table 2. T-test of N-Gain of algebraic thinking based learning.

\begin{tabular}{cccc}
\hline Learning & Comp. N-Gain & $\mathrm{t}$ & Sig. (2-tailed) \\
\hline RME : Expository & $0,61641: 0,41132$ & 6,600 & 0,000 \\
\hline
\end{tabular}

Table 2 shows that the probability value (significance) N-Gain of algebraic thinking is less than 0.05 . This means that there is a significant difference in the improvement of students' algebraic thinking between RME and expository learning. By considering the average value of $\mathrm{N}$-Gain algebraic thinking of the two groups of learning, it can be concluded that the overall enhancement in the algebraic thinking ability of students who received learning of RME is better than students who received expository learning.

RME as a learning innovation that begins with a realistic situation has helped students to master the concept of algebra gradually, by formalizing progressively [27]. Students are allowed to reinvent the concept of algebra, so that algebraic mastery can be better, more meaningful, and can master formal algebra material [32], as a representation of the increased ability of students to think algebra.

\subsection{Data Analysis of Algebraic Thinking Ability Based Learning and Initial Mathematical Knowledge}

Data on algebraic thinking ability of students consisting of the pretest average, posttest average, N-Gain average, and standard deviation (SD) based on students' initial mathematical knowledge (IMK) are presented in Table 3.

Table 3. Data on algebraic thinking based learning and initial mathematical knowledge.

\begin{tabular}{llrcrrrr}
\hline \multirow{2}{*}{ IMK } & \multirow{2}{*}{ Statistic } & \multicolumn{3}{c}{ RME Learning } & \multicolumn{3}{c}{ Expository Learning } \\
\cline { 3 - 7 } & & Pretest & Posttest & N-Gain & Pretest & Posttest & N-Gain \\
\hline \multirow{2}{*}{ Top } & Average & 6,70588 & 18,52941 & 0,76995 & 6,59091 & 14,27273 & 0,49957 \\
\multirow{2}{*}{ Middle } & SD & 2,17269 & 1,69991 & 0,11177 & 1,00755 & 3,11955 & 0,19632 \\
& Average & 6,24000 & 15,08000 & 0,55999 & 6,13636 & 11,72727 & 0,35282
\end{tabular}




\begin{tabular}{llcccccc} 
& SD & 2,63439 & 3,46314 & 0,20564 & 1,39029 & 1,98042 & 0,11775 \\
\multirow{2}{*}{ Low } & Average & 5,14815 & 14,74074 & 0,57198 & 5,19048 & 11,66667 & 0,38014 \\
& SD & 1,89541 & 2,78171 & 0,14905 & 1,60060 & 2,55604 & 0,16898 \\
\hline
\end{tabular}

Table 3 shows that at each level of initial mathematical knowledge, an RME class and an expository class have a slightly same average of pretest of algebraic thinking. For the top of initial mathematical knowledge, an RME class and an expository class have algebraic thinking pretest average consecutively as much as 6,70588 and 6,59091. For the middle of initial mathematical knowledge, an RME class and expository class have algebraic thinking pretest average consecutively as much as 6,24 and 6,13636. For the low of initial mathematical knowledge, an RME class and an expository class have algebraic thinking pretest average consecutively as much as 5,14815 and 5,19048.

After the learning process, students' algebraic thinking ability from both groups has increased. For the top of initial mathematical knowledge, RME and expository students get an average of 18,52941 of algebraic thinking (enhancing as much as 0,76995) and expository students get an average of 14,27273 of algebraic thinking (enhancing as much as 0,49957 ). For the middle initial mathematical knowledge, RME students who get an average of 15,080 algebraic thinking (enhancing as much as 0,55999) and the expository students get an average of 11,72727 of algebraic thinking (enhancing as much as 0,35282). In the low of initial mathematical knowledge, RME students get an average of 14,74074 of algebraic thinking (enhancing as much as 0,57198) and the expository students get an average of 11,66667 algebraic thinking (enhancing as much as 0,38014).

The above result indicates that there is a difference of algebraic thinking enhancement between the group of the student receiving RME and group of students receiving expository at each initial mathematical knowledge level. The results of the difference between RME learning and expository learning are presented in the following table.

Table 4. T-test N-Gain algebraic thinking based on learning and initial mathematical knowledge.

\begin{tabular}{ccccc}
\hline IMK & Learning & Comp. N-Gain & t or t' & Sig. (2-tailed) \\
\hline Top & RME : Expository & $0,76995: 0,49957$ & 5,118 & 0,000 \\
Middle & RME : Expository & $0,55999: 0,35282$ & 4,109 & 0,000 \\
Low & RME : Expository & $0,57198: 0,38014$ & 3,845 & 0,000 \\
\hline
\end{tabular}

Table 4 shows that for each initial mathematical knowledge category, the probability value (Sig.) of data N-Gain of algebraic thinking is less than 0.05. This means that there is a significant difference in the improvement of students' algebraic thinking ability between RME and expository learning for each level of initial mathematical knowledge. By considering the average N-Gain of algebraic thinking at every initial mathematical knowledge level for both groups, we can conclude that for all levels of initial mathematical knowledge, enhancement average of algebraic thinking ability of students who received RME is better than that of students received expository. Algebraic thinking of students in each initial mathematical knowledge has a different enhancement. The difference in algebraic thinking enhancement between the class of RME and Expository in each initial mathematical knowledge is as follows: $0.76995-0.49957$ $=0.27038$ for top initial mathematical knowledge; $0.55999-0.35282=0.20717$ for middle initial mathematical knowledge; and $0.57198-0.38014=0.19184$ for low initial mathematical knowledge. This means that students who have the biggest advantage of RME learning are students with top initial mathematical knowledge. This is because algebraic thinking requires 
good reasoning abilities. This demand can be said to be a relatively high demand for eighthgrade students, who are at the level of analysis of taxonomy bloom [33].

\section{Conclusion}

Based on the results of the research and the explanation revealed above, we come to the conclusions as follows: (a) Perceived from whole aspects of learning, the overall enhancement of algebraic thinking ability of students who receive learning of RME is better than that of students who take the expository learning; (b) Perceived from learning aspect and students' initial mathematical knowledge, at every level of initial mathematical knowledge, the enhancement of algebraic thinking ability of students who receive learning of RME is better than that of students who receive the expository learning. Students who benefit the most from RME learning are students with the best initial mathematical knowledge.

\section{References}

[1] Mintos, A., Hoffman, A.J., Kersey, E., Newton, J., Smith, D.: Learning about issues of equity in secondary mathematics teacher education programs. Journal of Mathematics Teacher Education. Vol. 22, pp 433-458 (2019)

[2] Moses, R., and Cobb, C.: Radical Equations: Math Literacy and Civil Right. Boston, MA: Beacon Press (2001)

[3] National Research Council, [NRC].: The Nature and Role of Algebra in the K-14 Curriculum. Washington, D.C : National Academy Press (1998)

[4] Pantazi, D. P., Chimoni, M., Christou, C.: Different Types of Algebraic Thinking: an Empirical Study Focusing on Middle School Students. International Journal of Science and Mathematics Education. pp. 1-20 (2019)

[5] Papadopoulos, I., Patsiala, N.: When the "Tug-of-War" Game Facilitates the Development of Algebraic Thinking. International Journal of Science and Mathematics Education. Vol. 17, pp 1401-1421 (2019)

[6] Chimoni, M., Pantazi, D. P., Christou, C.: Examining early algebraic thinking: insights from empirical data. Educational Studies in Mathematics. pp. 57-76 (2018)

[7] Kieran, C.: Seeking, Using, and Expressing Structure in Numbers and Numerical Operations: A Fundamental Path to Developing Early Algebraic Thinking. Teaching and Learning Algebraic Thinking with 5- to 12-Year-Olds. pp. 79-105 (2018)

[8] Pang, J., S., and Kim, J., W.: Characteristics of Korean Students' Early Algebraic Thinking: A Generalized Arithmetic Perspective. Teaching and Learning Algebraic Thinking with 5- to 12Year-Olds. pp. 141-165 (2018)

[9] Radford, L.: The Emergence of Symbolic Algebraic Thinking in Primary School. Teaching and Learning Algebraic Thinking with 5- to 12-Year-Olds. pp. 3-25 (2018)

[10] Stewart, S. and Reeder, S.: Algebra Underperformances at College Level: What Are the Consequences?. And the Rest is Just Algebra. pp. 3-18 (2017)

[11] Asquith, P., Stephens, A.C., Knuth, E.J.: Middle School Mathematics Teachers' Knowledge of Students' Understanding of Core Algebraic Concepts: Equal Sign and Variable. Mathematical Thinking and Learning. pp. 249 - 272 (2007)

[12] Kriegler, S., and Lee, T.: Using Standardized Test Data as Guidance for Placement into $8^{\text {th }}$ Grade Algebra. Los Angeles: University of California (2007)

[13] Lawrence, A., and Hennessy, C.: Lessons for Algebraic Thinking: Grade 6 - 8. Sausalito: Math Solutions Publications (2002) 
[14] Vance, J. H.: Number Operations from An Algebraic Perspective. Teaching Children Mathematics. pp. 282-285 (1998)

[15] Usiskin, Z.: Conceptions of School Algebra and Uses of Variables. Algebraic Thinking, Grades K-12: Reading from NCTMs School-Based Journal and Other Publications. pp.7-13 (1999)

[16] Kilpatrick, J., Swafford, J., and Findell, B.: Adding it Up, Helping Children Learn Mathematics. Washington, DC: National Academy Press (2001)

[17] Herbert, K., and Brown, R. H.: Patterns as tools for algebraic reasoning. Teaching Children Mathematics. pp. 340-344 (1997)

[18] Revina. S., and Leung, F., K., S.: How the Same Flowers Grow in Different Soils? The Implementation of Realistic Mathematics Education in Utrecht and Jakarta Classrooms. International Journal of Science and Mathematics Education, pp. 565-589 (2019)

[19] Sawatzki, C., Downton, A., and Cheeseman, J.: Stimulating proportional reasoning through questions of finance and fairness. Mathematics Education Research Journal. Pp. 1-20 (2019).

[20] Tzur R.: Developing Fractions as Multiplicative Relations A Model of Cognitive Reorganization. Constructing Numbers: Merging Perspectives from Psychology and Mathematics Education. pp.163-192 (2019)

[21] Lange, D.: Using and Appying Mathematics in Education. International Handbook of Mathematics Education. pp. 49-97 (1996)

[22] Gravemeijer, K.P.E.: Developing Realistic Mathematics Education. Utrecht: Freudenthal Institute (1994)

[23] Panhuizen, M., H.: Seen Through Other Eyes-Opening Up New Vistas in Realistic Mathematics Education Through Visions and Experiences from Other Countries. International Reflections on the Netherlands Didactics of Mathematics: Visions on and Experiences with Realistic Mathematics Education. pp. 1-20 (2019)

[24] Drijvers, P., Buitenhuis, H. K., Doorman, M.: Assessing mathematical thinking as part of curriculum reform in the Netherlands. Educational Studies in Mathematics. pp. 1-22 (2019)

[25] Kilhamn, C. Lindberg, A., S., R., Björkqvist, O.: School Algebra. Encountering Algebra. pp. 1-12 (2019)

[26] Freudenthal, H.: Revisiting Mathematics Education. China Lectures. Dordrecht: Kluwer Academic Publishers (1991)

[27] Webb, D. C and Peck, F. A.: From Tinkering to Practice-The Roleof Teachers in the Application of Realistic Mathematics Education Principles in the United States. International Reflections on the Netherlands Didactics of Mathematics: Visions on and Experiences with Realistic Mathematics Education. pp. 21-39 (2019)

[28] Wittmann, E. C.: The Impact of Hans Freudenthal and the Freudenthal Institute on the Project Mathe 2000. International Reflections on the Netherlands Didactics of Mathematics: Visions on and Experiences with Realistic Mathematics Education. pp. 63-69 (2019)

[29] Ponte, J. P and Brocardo, J.: Echoes and Influences of Realistic Mathematics Education in Portugal. International Reflections on the Netherlands Didactics of Mathematics: Visions on and Experiences with Realistic Mathematics Education. pp. 209-228 (2019)

[30] Lee, K.H., Chong, Y. O., Na, G. S. and Park, J. H.: Korean Mathematics Education Meets Dutch Didactics. International Reflections on the Netherlands Didactics of Mathematics: Visions on and Experiences with Realistic Mathematics Education. pp. 279-296 (2019)

[31] Treffers, A.: Didactical Background of a Mathematics Program for Primary Education. Realistic Mathematics Education in Primary School. pp. 21-56 (1991)

[32] Zolkower, B., Bressan, A. M., Pérez, S. and Gallego, M. F.: From the Bottom Up-Reinventing Realistic Mathematics Education in Southern Argentina. International Reflections on the Netherlands Didactics of Mathematics: Visions on and Experiences with Realistic Mathematics Education. pp. 133-166 (2019)

[33] Krishnan, R.: Achieving Cognitive Skills in Multimedia Through Revised Bloom Taxonomy. Creative Business and Social Innovations for a Sustainable Future. Pp. 11-20 (2019) 